\title{
Decay Detection in an Ancient Column with Combined Close-Range Photogrammetry (CRP) and Ultrasonic Tomography
}

\author{
Giuseppe Casula ${ }^{1, *(D)}$, Silvana Fais ${ }^{2,3} \mathbb{D}$, Francesco Cuccuru ${ }^{2} \mathbb{D}$, Maria Giovanna Bianchi ${ }^{1} \mathbb{D}$, Paola Ligas $^{2} \mathbb{D}$ \\ and Alessandro Sitzia 4
}

1 Istituto Nazionale di Geofisica e Vulcanologia (INGV)—Sezione di Bologna, Via Donato Creti 12, 40128 Bologna, Italy; mariagiovanna.bianchi@ingv.it

2 Department of Environmental Civil Engineering and Architecture (DICAAR), University of Cagliari, Via Marengo 2, 09123 Cagliari, Italy; sfais@unica.it (S.F.); cuccuruf@unica.it (F.C.); pligas@unica.it (P.L.)

3 Consorzio Interuniversitario Nazionale per l'Ingegneria delle Georisorse, CINIGEO, Palazzo Baleani, Corso Vittorio Emanuele II, 00186 Roma, Italy

4 Ministero dei Beni e delle Attività Culturali, Direzione Regionale Musei Sardegna, Largo Carlo Felice 15, 09100 Cagliari, Italy; alessandro.sitzia@beniculturali.it

* Correspondence: giuseppe.casula@ingv.it; Tel.: +39-0514151415

check for updates

Citation: Casula, G.; Fais, S.; Cuccuru, F.; Bianchi, M.G.; Ligas, P.; Sitzia, A. Decay Detection in an Ancient Column with Combined Close-Range Photogrammetry (CRP) and Ultrasonic Tomography. Minerals 2021, 11, 1114. https://doi.org/ $10.3390 / \min 11101114$

Academic Editor: Adrián Durán Benito

Received: 20 September 2021

Accepted: 7 October 2021

Published: 11 October 2021

Publisher's Note: MDPI stays neutral with regard to jurisdictional claims in published maps and institutional affiliations.

Copyright: (c) 2021 by the authors. Licensee MDPI, Basel, Switzerland. This article is an open access article distributed under the terms and conditions of the Creative Commons Attribution (CC BY) license (https:/ / creativecommons.org/licenses/by/ $4.0 /)$.
Abstract: This study presents the integrated application of a few non-destructive techniques, i.e., Close Range Photogrammetry (CRP), and low frequency $(24 \mathrm{kHz})$ ultrasonic tomography complemented by petrographical analysis. The aim here is to assess the conservation state of a Carrara marble column in the Basilica of San Saturnino, which is part of a V-VI century Palaeo Christian complex in the city of Cagliari (Italy). The high resolution 3D modelling of the studied artifact was computed starting from the integration of proximal sensing techniques, such as CRP based on the Structure from Motion (SfM) technique, which provided information on the geometrical anomalies and reflectivity of the investigated marble column surface. The inner parts of the studied body were inspected successfully in a non-invasive way by computing the velocity pattern of the ultrasonic signal through the investigated materials, using 3D ultrasonic tomography. The latter was optimally designed based on the 3D CRP analysis and the locations of the source and receiver points were detected as accurately as possible. The integrated application of in situ CRP and ultrasonic techniques provided a full 3D high resolution model of the investigated artifact, which made it possible to evaluate the material characteristics and its degradation state, affecting mainly the shallower parts of the column. The 3D visualisation improves the efficiency, accuracy, and completeness of the interpretative process of data of a different nature in quite easily understood displays, as well as the communication between different technicians.

Keywords: close range photogrammetry; 3D ultrasonic tomography; petrographic analyses; marble; degradation

\section{Introduction}

The diagnosis of the conservation state of monumental structures, from the constraints to the spatial distribution of their physical properties on shallow and inner building materials, represents one of the key objectives in the application of non-invasive techniques.

In the field of cultural heritage, the complex task of the diagnostics of the state of conservation of ancient monuments is a topic that involves many subjects, such as public and private institutions, civil protections, etc. Moreover, the economic aspect is to be taken into account, since the monitoring and intervention for the maintenance of monumental structures often require the outlay of important financial resources [1,2]. Non-destructive tests can be used to obtain the necessary qualitative and quantitative parameters needed to plan the recovery and preservation of a monumental structure.

Non-destructive techniques are constantly being improved in many fields of the applied sciences, as described by numerous authors [3-13]. For instance, contactless remote 
and proximal sensing methods can represent an optimal solution for the 3D accurate modelling of architectural elements. Among proximal sensing techniques, the Close Range Photogrammetry (CRP) survey based on the Structure from Motion (SfM) methodology enhances cost-effective surveys and technical expertise. SfM is based on computer vision and facilitates photogrammetric reconstruction from single or multiple arrays of digital photos. The higher spatial and spectral resolutions of sensors available for SfM photogrammetry improve the diagnostic analysis, especially in the knowledge phase. Moreover, they facilitate the monitoring of the conservation state of monumental structures, allowing for the attainment of natural colour in-time (time-lapse) texturized 3D models. The 3D CRP model can be computed from the overlapping images, without the necessity of prerequisite information on camera location and orientation, camera calibration, and/or surveyed reference points, allowing for the use of inexpensive imaging platforms [14]. A few other techniques, such as the Terrestrial Laser Scanner (TLS) [15,16] and fluorescence Light Detection And Ranging (LIDAR) [17], are very useful for analysing the shallow parts of stone building materials, allowing for the inspection of large surfaces without any contact or damage to them. Other non-invasive geophysical techniques, such as Magnetic Resonance Imaging (MRI) [18] and Infrared Thermography (IRT) [19,20], are useful for probing just below the surface materials. The quantitative analysis of thermography applied to architectural structures allows an effective diagnosis of the decay of shallow materials, as well as the identification of the possible causes of their weakness [21]. While other techniques, such as the ultrasonic ones based on the analysis of the propagation of ultrasonic signals, inspect inside the materials $[3-6,8,9,22-30]$. The ultrasonic velocity distribution is strictly related to the physical condition of the rocks and to many petrophysical characteristics. This relation is different for different types of rocks and strictly depends on the rock-forming minerals, chemical composition, type of porosity, density, elastic moduli, fracturing, and weathering [23,25,31-36]. Internal geometry, such as grain shape and size, texture, and bonding properties have a great influence on ultrasonic wave propagation, which assumes a strong diagnostic power in the analysis of the conservation state of natural stone materials.

In the non-invasive characterisation of materials, the integration of different types of complementary information can improve the analysis and the diagnostic process. This is of paramount importance in many fields of the applied research, such as the cultural heritage, engineering geology, mining, and forestry. However, it is worth highlighting that efficiency in the multi-technique and multi-scale integrated approaches is possible if the integration is performed appropriately and combined with a good knowledge of the material characteristics. In this way, the integration of heterogeneous data becomes more agile and feasible, thus improving the complementarity of different techniques.

In this study, we present the integrated application of different non-destructive techniques, i.e., CRP and low frequency $(24 \mathrm{kHz})$ ultrasonic tomography complemented by petrographical analysis, which is based on Optical Microscopy (OM).

The intrinsic characteristics of the materials that make up a monumental structure and affect some properties (e.g., reflectivity, geometrical anomalies, and longitudinal velocity) through the above methods differ substantially. Consequently, the content of their information is mainly complementary rather than redundant. In particular, the CRP technique plays a fundamental role in the planning and interpretation phases of 3D ultrasonic tomography, providing 3D high resolution measurable models on which to carry out a huge quantity of measurements (e.g., precise locations of the source and receiver points), which is indispensable in rendering the 3D ultrasonic data at their precise location.

This integrated methodology has been applied to a Carrara marble column in the Basilica of San Saturnino (Figure 1a,b), also called the Church of Saints Cosma and Damiano, in Byzantine-Proto-Romanesque style, which is part of the Palaeo-Christian complex of the V-VI century. Moreover, the complex includes the adjacent Christian necropolis in the square of San Cosimo in the city of Cagliari, Italy. The church has a complex history and has undergone destruction, restoration, and reconstruction over the centuries. As a 
result, architectural elements from the most ancient periods can be found inside the church, together with other more recent elements.

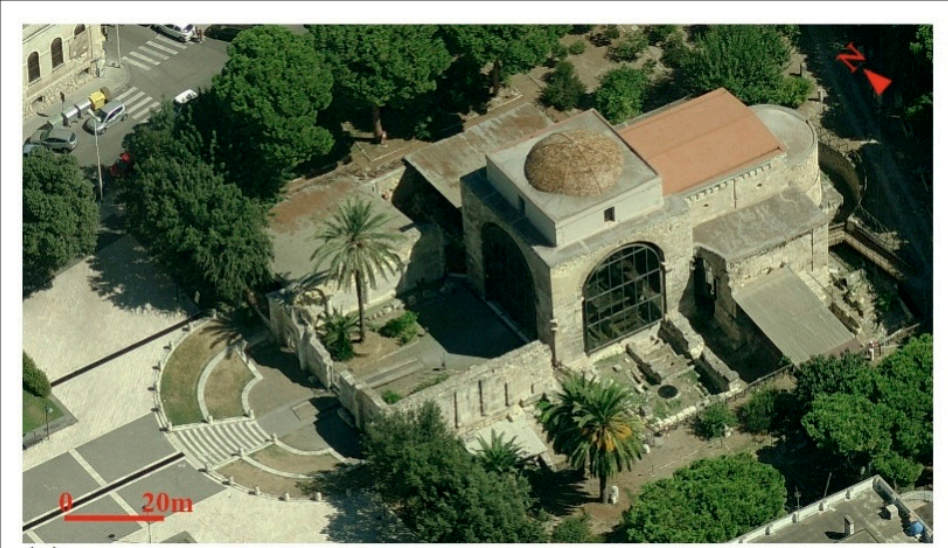

(a)

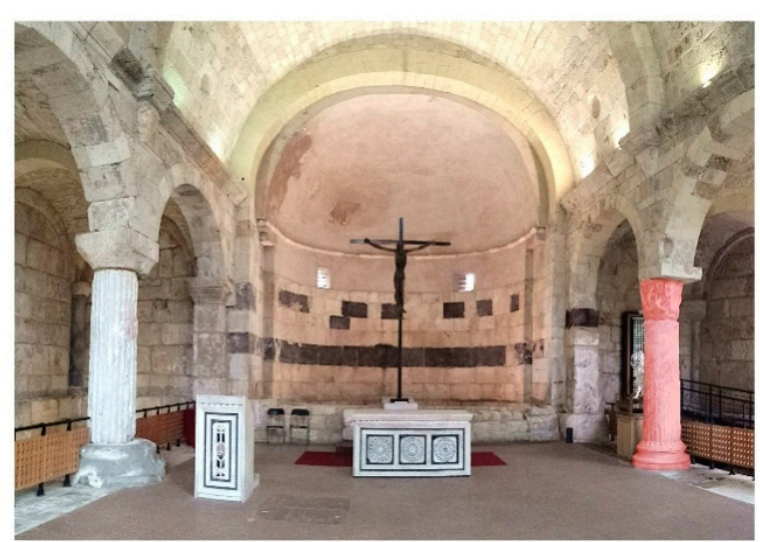

(b)

Figure 1. San Saturnino Basilica: (a) Panoramic image of the monument (Lat: 39.213986 North—Long: 9.123167 East modified from http://www.sardegnageoportale.it/webgis2/sardegnafotoaeree/); (b) central nave of the Basilica with the studied column highlighted in red.

The high resolution 3D modelling of the studied artifact was computed starting from the integration of proximal sensing techniques, such as CRP based on Structure from Motion (SfM), which gave information on the geometrical anomalies and reflectivity of the surface of the investigated marble column. The inner parts of the studied body were successfully inspected in a non-invasive way by computing the velocity pattern of the ultrasonic signal through the investigated materials, using 3D ultrasonic tomography. This technique gives information on the elastic properties of the material related with petrophysical and mechanical properties and a number of factors, such as the presence of fractures, voids, and flaws. Extracting information on these factors, from the elastic wave velocity using 3D tomography, provides a non-invasive approach to analysing the property changes of the inner material of the ancient column.

The integrated application of in situ CRP and ultrasonic techniques provides a full 3D high resolution model of the investigated artifact. This model, which is enhanced by the knowledge of the petrographic characteristics of the materials, affords reliable information on the state of conservation of the materials used in the construction process. The noninvasive integrated approach is helpful in deciding whether any repair is needed, how to choose the optimal repair techniques, and in prioritising interventions for the restoration and future preservation $[5,8,30]$.

\section{Materials and Methods}

\subsection{Macroscopic Features}

The column under study is located in a closed environment (inside the Basilica of San Saturnino) with no constant air recirculation and high values of relative humidity, that caused severe superficial alteration phenomena in the column. In these environmental conditions, the building material which is of a carbonate nature, suffered the effects of calcite solubilization and intercrystalline decohesion, that led to more serious problems, such as an increase in porosity, exfoliation, and pulverisation. The product of pulverization is characterised by a highly hygroscopic marble dust that accumulates in the protruding parts of the column base (Figure 2). Since this dust is rich in moisture, if not routinely removed, it could trigger phenomena of alteration and dissolution that could seriously damage even the base of the structure itself, which is not yet compromised at present. However, other sectors of the column such as the upper and central part of the shaft have suffered the greatest damage due to exfoliation and pulverization. The loss of material in 
these critical sectors caused a localised reduction in volume, implying dangerous conditions, such as a possible worsening of the mechanical characteristics of the marble [37].

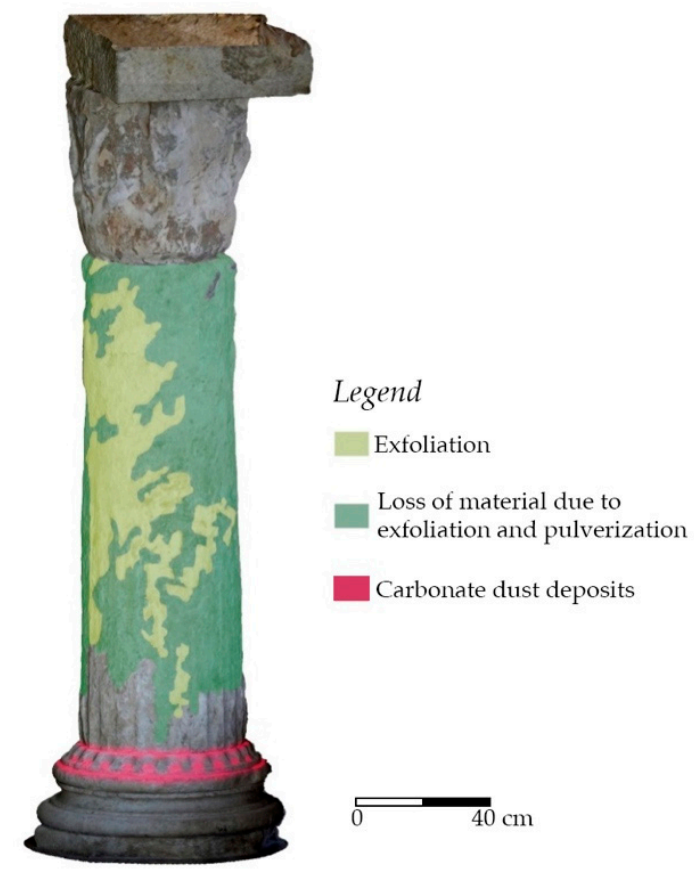

Figure 2. Degradation forms affecting the analysed column shaft.

\subsection{Optical Microscopy Analysis}

Optical Microscopy $(\mathrm{OM})$ was used for the analysis of the compositional, textural, and some petrophysical characteristics, such as the porosity of the studied building material. Optical microscopy was performed with a Carl Zeiss Axioplan microscope (Carl Zeiss, Oberkochen, Germany).

Thin sections were obtained from some fragments of material detached from the shallow part of the column shaft. It was decided to study this material mainly in order to not carry out further destructive tests on the column, as well as to evaluate the influence of degradation on texture and composition at a microscopic level.

From the OM observations, the building material was identified as marble with a granoblastic texture (Figure 3). The calcite crystals have an average size of about $200 \mu \mathrm{m}$ with minimum and maximum dimensions of 60 and $600 \mu \mathrm{m}$, respectively. The crystals, generally characterised by straight boundaries, are interconnected by a triple junction with an angle of approximately $120^{\circ}$ (Figure 3a). Based on the dimensional and geometric characteristics of the calcite crystals, this type of marble could be geographically attributed to the marble basin of the Apuan Alps in Italy [38].

In the studied marble, the crystals are mutually well welded (Figure 3b). However, in several sectors, there is no direct contact and they can be separated by open fractures of a width of $500 \mu \mathrm{m}$ on average (Figure 3c). The fractures represent the main type of porosity (about $2 \%$ ), subsequent to the superficial degradation phenomena, such as dissolution and exfoliation, which can also be observed at the macroscopic level. The fractures became sectors of accumulation of altered material and dirt (Figure 3c,d), whose nature must be assessed in further analysis. By infiltrating into the intercrystalline spaces, these materials further intensified both the alteration processes and the general degradation of the stone material. 

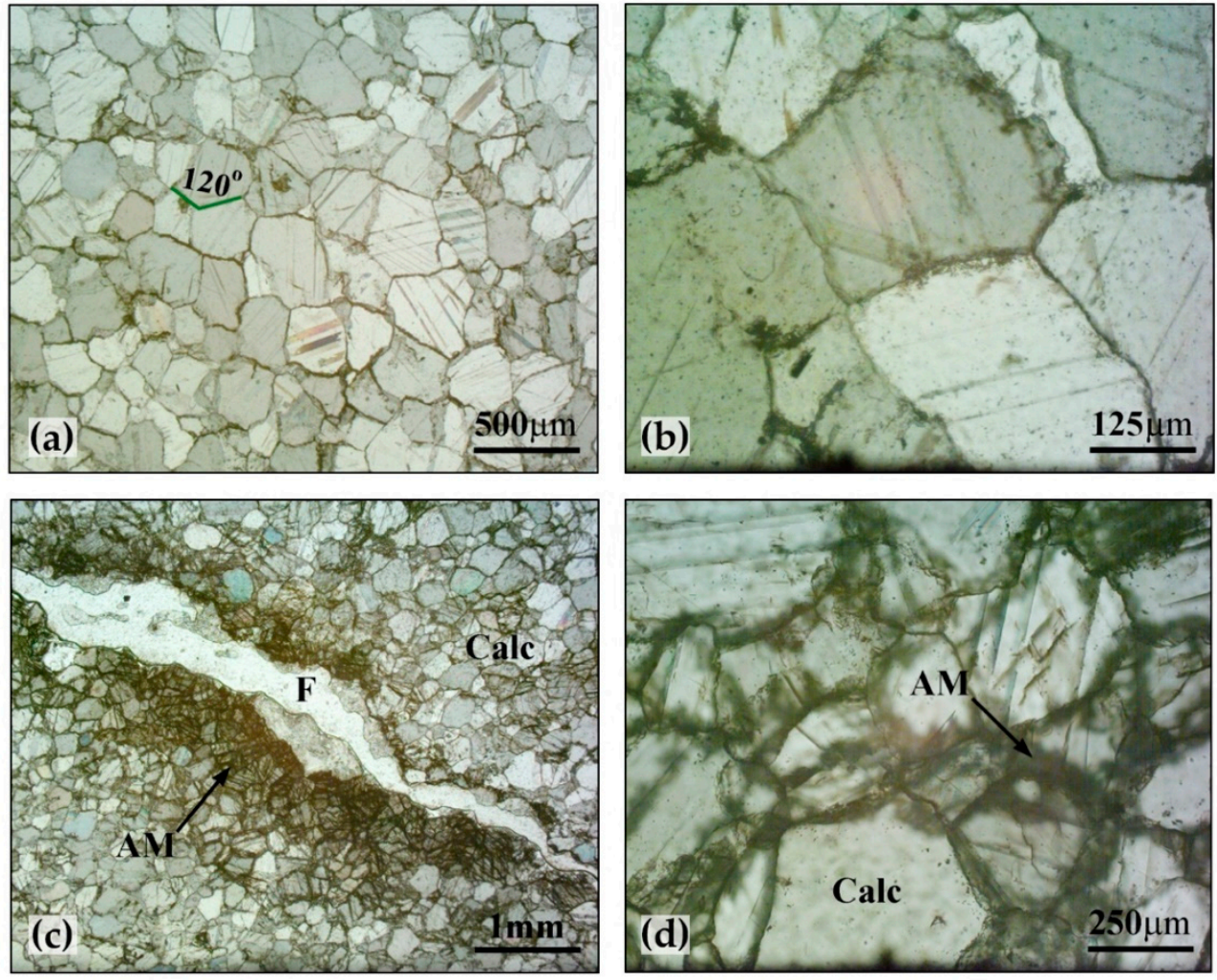

Figure 3. Petrographic thin section images. (a) Granoblastic texture of the marble and contact angle $\left(120^{\circ}\right)$ between the calcite crystals. Cross polarised light; (b) detail of well welded boundaries among calcite crystals. Cross polarised light; (c) alteration material (AM) concentrated on the edges of a fracture (F). Calc (calcite). Cross polarised light; (d) detail of a fractured sector characterised by the alteration material (AM) and dirt between calcite crystals (Calc). Cross polarised light.

\subsection{Close Range Photogrammetry}

CRP is a proximal sensing methodology, which uses accurate imaging techniques to analyse the three-dimensional shape of a wide range of manufactured and natural objects. CRP is based on Structure from Motion algorithms and software facilities.

Structure from Motion (SfM) is a Remote Sensing (RS) methodology that uses multiple arrays of high quality 2D digital photographs to 3D-model the surface of a studied object, by creating a dense point cloud texturised with natural colours. Moreover, the $X, Y, Z$ coordinates are associated with each point of this cloud in an intrinsic reference frame, defined by the user that can be successively refined using geo-referenced Ground Control Points (CGPs). Multiple 2D digital images must be acquired using photo-cameras evenly spaced all around the observed objects from different perspectives and processed with SfM-based facilities. In practice, the structure of the studied object is 3D-modelled by means of the camera movement [14,39].

Initially, the software automatically identifies the most prominent features (key-points) that can be immediately recognised in multiple photographs by means of algorithms. These algorithms can provide Robust Feature Detection and Matching (RFDM), such as the ScaleInvariant Feature Transform (SIFT) [40]. In a second stage, the images that were previously quality-checked (carefully selected) by the operator are aligned very precisely using bundle adjustment algorithms as well [41] and a sparce point cloud is generated. In the third step, this cloud is used as input in the computation of the final unstructured unified dense point cloud representing the high resolution 3D-model of the studied body, by means of Multi Video Stereo view (MVS) styled algorithms $[3,4,6,9,25]$. 


\subsubsection{The Photogrammetric Survey}

To compute the HR 3D-model of an ancient marble column in the Basilica of San Saturnino in the town of Cagliari, we used a Nikon D-5300 24.2 MP CMOS digital camera mounted on a tripod equipped with a bubble level (Figure 4a). After an in situ successful feasibility inspection, we acquired 102 digital photos evenly spaced all around the studied artifact and from different perspectives (Figure $4 \mathrm{~b}$ ). The higher the number and optical resolutions of the acquired photos, the higher the precision of the resulting final model, which can have a resolution higher than $1 \mathrm{~mm}$ or more. In order to obtain the optimal degree of image superposition (60\% to $80 \%$ ) required to optimize the image processing, the station points (poses) were settled according to the following conditions: (1) At fixed distances (1 $\mathrm{m}$ to $3 \mathrm{~m}$ ) from the column (Figure 4c); (2) the space (baselines) between them was maintained as small as possible (less than $1 \mathrm{~m}$ ); (3) the images were acquired as far as possible at homogeneous exposure conditions; and (4) reference markers (calibrated bars) were introduced in the scene (Figure $4 \mathrm{~d}$ ).

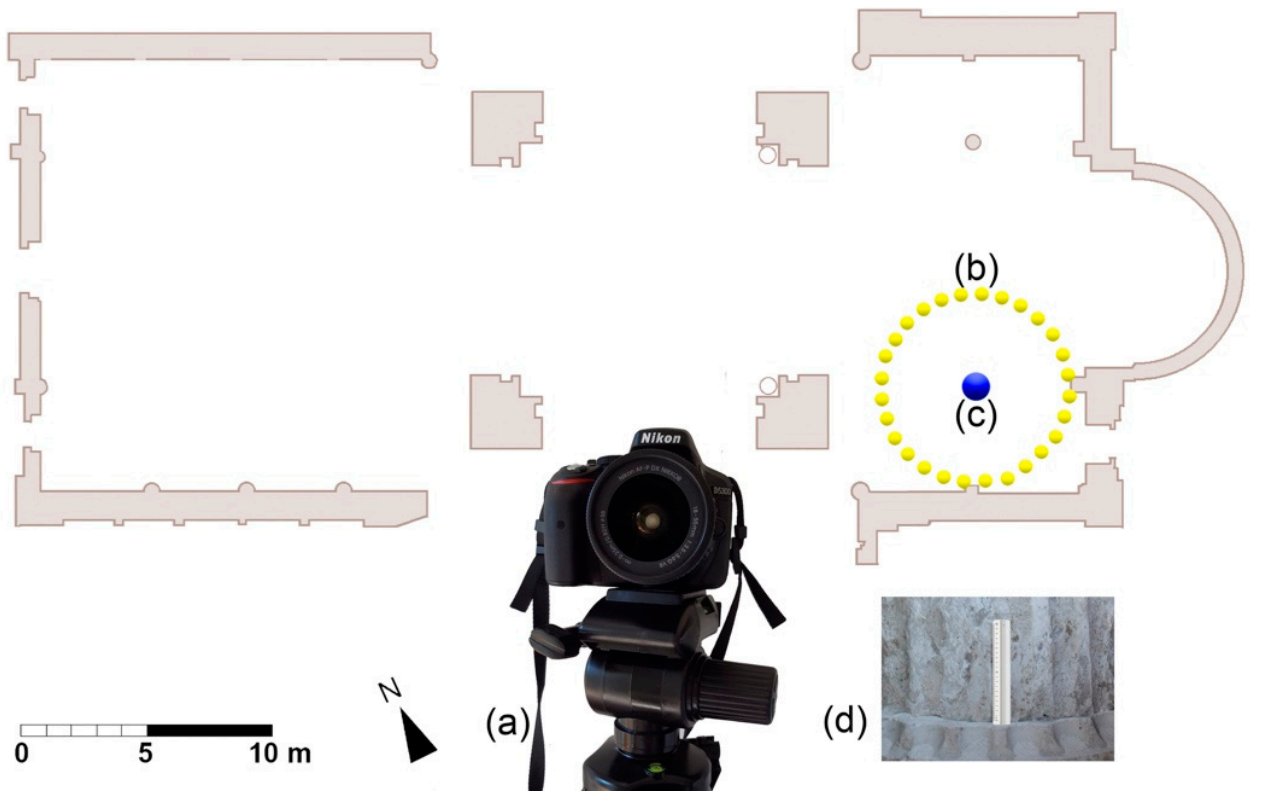

Figure 4. Plan of the Basilica of San Saturnino showing the scheme of the CRP survey of the investigated column. (a) Nikon D5300 digital camera used in this work; (b) camera positions (yellow circles in the figure); (c) studied column (blue circle); (d) calibrated bar introduced in the scene superimposed to the base of the studied column.

\subsubsection{Data Processing}

The Agisoft-Metashape v1.6.3 (Agisoft LLC, St. Petersburg, Russia) software was used to pre-process in the best way the 102 images acquired in situ during the August 2020 photogrammetric campaign. The software was operated on two multicore/multithreads processor PCs equipped with GPUs with Compute Unified Device Architectures (CUDA) v8.0 (NVIDIA Corp., Santa Clara, CA, USA) cores under Linux openSuse Leap v15.1 (C) 2015-2021 SUSE LLC, Nürnberg, Germany) and Microsoft Windows ${ }^{\circledR}$ O.S. v10 (Microsoft Corp., Redmond, WA, USA), respectively. For future developments, we are planning to run the data processing on High Power Computing (HPC).

Images are selected and aligned in a very precise way using the bundle adjustment algorithms implemented in the software, as well. Moreover, key-points are located and a sparce point cloud is generated. Then, a dense unified unstructured point cloud texturized with natural colours in a red, green, blue (RGB) colour scale is obtained in the last step of SfM data elaboration. Finally, the resulting dense cloud of about 6 million points is format converted in the E57 LIDAR data exchange format, which is compatible with the input of cloud processing packages. 
At this stage of the CRP data processing, we used the algorithm implemented in the cloud processing software JRC-3D Reconstructor ${ }^{\circledR}$ v4.1.2 (Gexcel, Brescia, Italy) [42] and Cloud Compare v2.11.3 (Copyright $^{\circledR}$ 2000,2001,2002 Free Software Foundation, Inc., Boston, MA, USA) [43] to provide the surface geometrical anomalies and reflectivity patterns of the studied column.

Point clouds are manually edited, filtered, and meshed using the Poisson surface reconstruction algorithm implemented in the software Reconstructor ${ }^{\circledR}$ to fill little gaps and to generate an HR meshed 3D model of the marble column of a 1x1 mm scale to be used as a reference model.

In order to perform an optimal comparison of CRP results with the patterns of ultrasonic velocity detected by the application of the 3D tomography, in the final step of CRP data processing we detected: (1) The residuals of the 3D model of the Carrara marble ancient column with respect to a meshed fitted cylinder adopted as reference (i.e., geometrical surface anomalies of the studied artifact); (2) the pattern of the reflectivity parameter representing the amplitude of the backscattered light after reflection on the targeted column surface, which gave interesting analogies with the geometrical anomalies.

Figure 5 represents the flow chart of the CRP data processing described above.

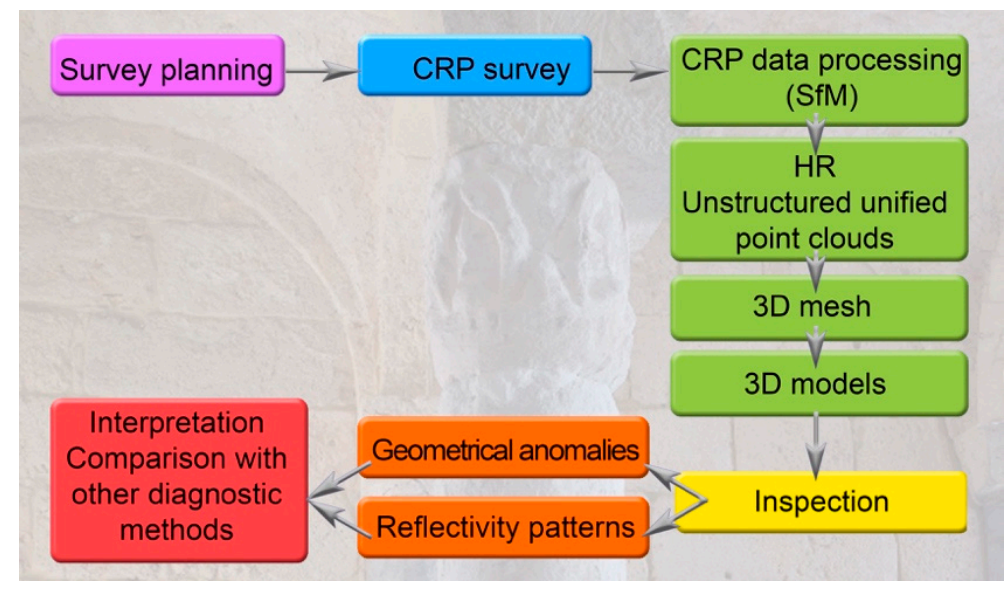

Figure 5. Flowchart of the SfM data processing.

\subsection{Ultrasonic Measurements}

Based on the 3D models with the previous technique (CRP and SfM photogrammetry), a 3D ultrasonic tomography was planned by designing a dense 3D survey to ensure a very good spatial coverage of the investigated column shaft. The 3D CRP model was indispensable to precisely locate the source and receiver stations for the 3D ultrasonic tomography, measure their mutual distance accurately, and detect their coordinates in the selected reference system (Cartesian system).

The ultrasonic experimental investigation on the column was aimed at determining the size and location of internal potential defects. In fact, after its propagation through the material, the ultrasonic signal is the result of the scattering and the delay in the transit times, which is caused by the presence of cracks, pores, and degradation zones that can change the internal structure of the stone material.

A Portable Ultrasonic Non-Destructive Digital Indicating Tester (Pundit Lab Plus) device by Proceq (Schwerzenbach, Switzerland) with $24 \mathrm{kHz}$ central frequency piezoelectric transducers, that can act as either a receiver or transmitter, was used to measure the travel time propagation of the longitudinal ultrasonic signal along many source-receiver paths. Moreover, each station was alternatively used as a transmitter and a receiver.

In this study, only the first arrival for each source-receiver path was taken into account, as this can be confidently associated with the longitudinal wave ( $\mathrm{P}$ wave). The transit time of the propagation of the longitudinal ultrasonic wave from the transmitter to the receiver was measured in a direct transmission mode [44,45]. The source and receiver 
positions lie along the perimeter of the investigated column shaft (Figure 6) in order to obtain a good ray coverage of the investigated volume. Every station point was spaced $15 \mathrm{~cm}$ along parallel vertical profiles in a way as to surround the investigated column shaft entirely and homogeneously, as well as to cross the investigated volume in many directions. Considering that the surface of the marble column is rough and irregular, special care was taken in choosing the best coupling agent between the transducer and material. As a coupling agent, silicone snug sheets were used. From previous experimental ultrasonic applications $[3,4,6,9,25]$, it was found that this kind of coupling agent is particularly suitable for use in porous media, such as natural materials. It optimises the transmissibility of the ultrasonic signal, filling the irregularities at the interface while avoiding soiling the material and interfering with it.

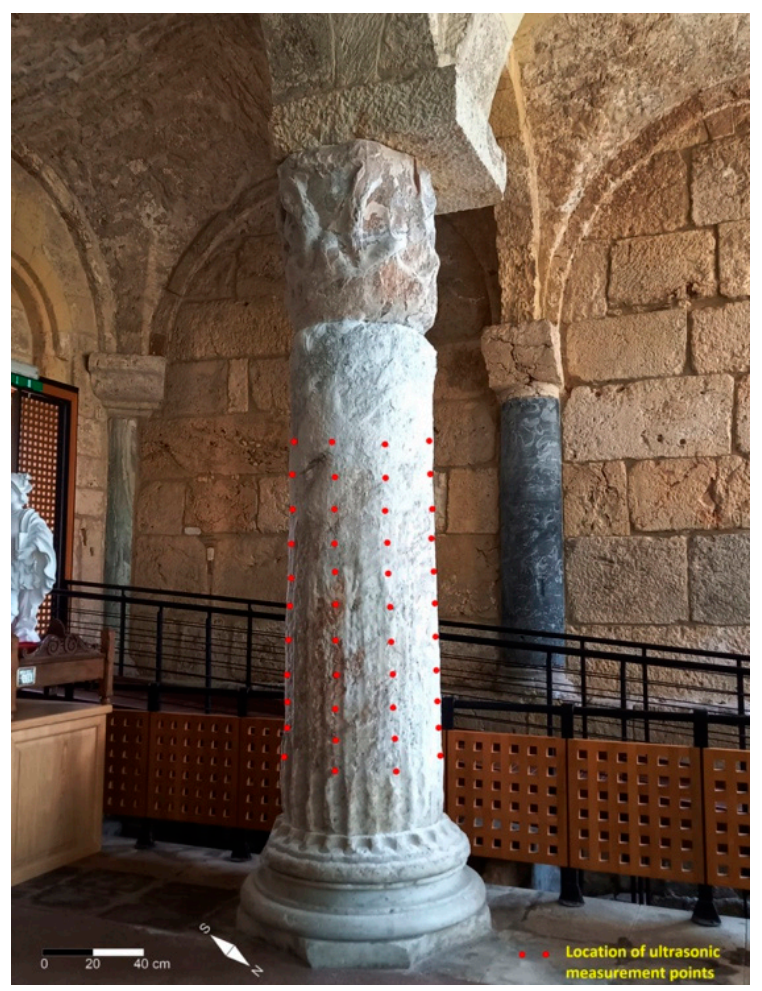

Figure 6. Location of the ultrasonic measurement points on the studied column.

The output signals were recorded by a portable digital oscilloscope (Fluke 96B) interfaced with a laptop to acquire and digitalise the ultrasonic waveforms for further analysis and processing.

The ultrasonic travel time along the source-receiver path was measured with an accuracy of $0.1 \mu$ s and a minimum of six measurements were assessed for each path. The transit times were measured by locating the first arrival times of the received longitudinal signals analyzing the waveforms recorded and displayed by the digital oscilloscope. In a complex situation as the studied one, the automated arrival picking techniques could not consistently detect first arrivals. Therefore, we carefully hand-picked the first arrivals of the longitudinal waves for the tomographic analysis. In fact, first-arrival picking plays an important role in the tomographic data processing and directly influences the quality of the results. Accordingly, the initial phase of the data processing was to carry out a quality control of the ultrasonic waveforms acquired by the digital oscilloscope. Later, a filtering to improve the Signal-to-Noise ratio $(\mathrm{S} / \mathrm{N})$ without modifying the intrinsic characteristics of the ultrasonic signal was carried out where necessary. The longitudinal wave velocity propagation between the source and receiver transducer pair can be directly estimated by considering the source-receiver distance divided by the travel time. This velocity is the result of effects of the material conditions along the ray path. 
The 3D Ultrasonic Tomography

A tomographic inversion, starting from the position of transmitters and receivers on a 3D Cartesian grid and the transit times between the source-receiver pair, was processed by considering curved rays and applying the well-known Simultaneous Iterative Reconstruction Technique (SIRT) [46-48] to produce the 3D velocity distribution model in the investigated volume. The ultrasonic measurements were 1936 from 88 point stations alternatively used as transmitter and receiver, but only 1860 of these were processed by the inversion technique. In fact, when checking the ultrasonic waveforms, only first arrivals with shapes that looked undistorted were taken into consideration. The investigated volume was discretized into elements (voxels). The size of the voxels was determined by the number of source-receiver paths. Thanks to the iterative procedure, it was possible to calculate the velocity of the longitudinal ultrasonic signal within each voxel. The iterative reconstruction technique involves a series of successive approximations to correct an arbitrary initial parameter distribution (starting velocity model). In order to obtain a realistic starting velocity model as input for the SIRT to invert travel-time data and produce a reliable 3D representation of the ultrasonic longitudinal wave velocity distribution inside the column, a methodology based on the cross-correlation function proposed by Fais and Casula (2010) [49] was applied. Omitting the detailed mathematical aspects of the inversion algorithm, the main steps involved in the inversion process are briefly the following: Forward computation of the model travel times for each source/receiver pair; computation of the theoretical travel times using the ray-tracing method; comparison of the theoretical and experimental travel times; and calculation of the residuals and application of velocity corrections due to time discrepancy to the $3 \mathrm{D}$ volume of the voxels within the model. The iterative sequence is repeated until the necessary accuracy is obtained. In this study, the entire processing sequence was repeated for 18 iterations. This amount of iterations was found appropriate to obtain the best representation of the 3D distribution of the longitudinal velocity within the investigated volume and a good compromise between the resolving power and the reliability of the velocity model.

The 3D rendering of the longitudinal velocity distribution inside the investigated volume was plotted by the software Voxler v.4.3.771 from Golden Software, which enables an efficient and accurate three-dimensional representation. With this kind of display, the ultrasonic velocity distribution data can be viewed as a volume. By scrolling through the data volume and rotating in any direction, one can get an easy feel of the elastic characteristics of the materials inside the column. Furthermore, to facilitate the interpretation of the 3D tomography model inside the data volume, it was sliced to create cross sections along its longitudinal development. In this way, the slices were created by slicing the 3D volume horizontally and deciding their position in an interactive manner. To understand how the low velocity zones associated with degraded zones are distributed within the investigated volume, it was effective to display the slices sequentially through the longitudinal axis of the volume. In this way, one can obtain a much better understanding of the spatial development of the altered and/or damaged zones inside the column.

\section{Results and Discussion}

The integrated use of different non-invasive techniques, such as CRP digital photogrammetry and 3D ultrasonic tomography, corroborated by the analysis of the petrographic characteristics of the investigated materials is of paramount importance in assessing the state of conservation of the shallow and deep zones of the marble making up the investigated structure. Knowledge of the stone material conditions and its decay processes, as well as the mechanisms governing them depend on the intrinsic properties of the investigated material, such as mineral composition, texture, nature, and distribution of porosity, as well as their interrelationship with the environmental exposure [50]. 


\subsection{Close Range Photogrammetry}

As previously described in the section on methodologies, starting from a dense point cloud texturised with natural colours represented with an RGB scale and computed using CRP and SfM methodologies (Agisoft-Metashape ${ }^{\circledR}$ package), we applied the algorithms for the cloud post-processing implemented in the JRC-3D Reconstructor ${ }^{\circledR}$ package to compute the geometrical anomalies and reflectivity patterns of the studied ancient Carrara marble column. The results of these computations are represented in Figure $7 \mathrm{a}, \mathrm{c}, \mathrm{d}$, together with the longitudinal velocity patterns obtained with low frequency ultrasonic tomography.

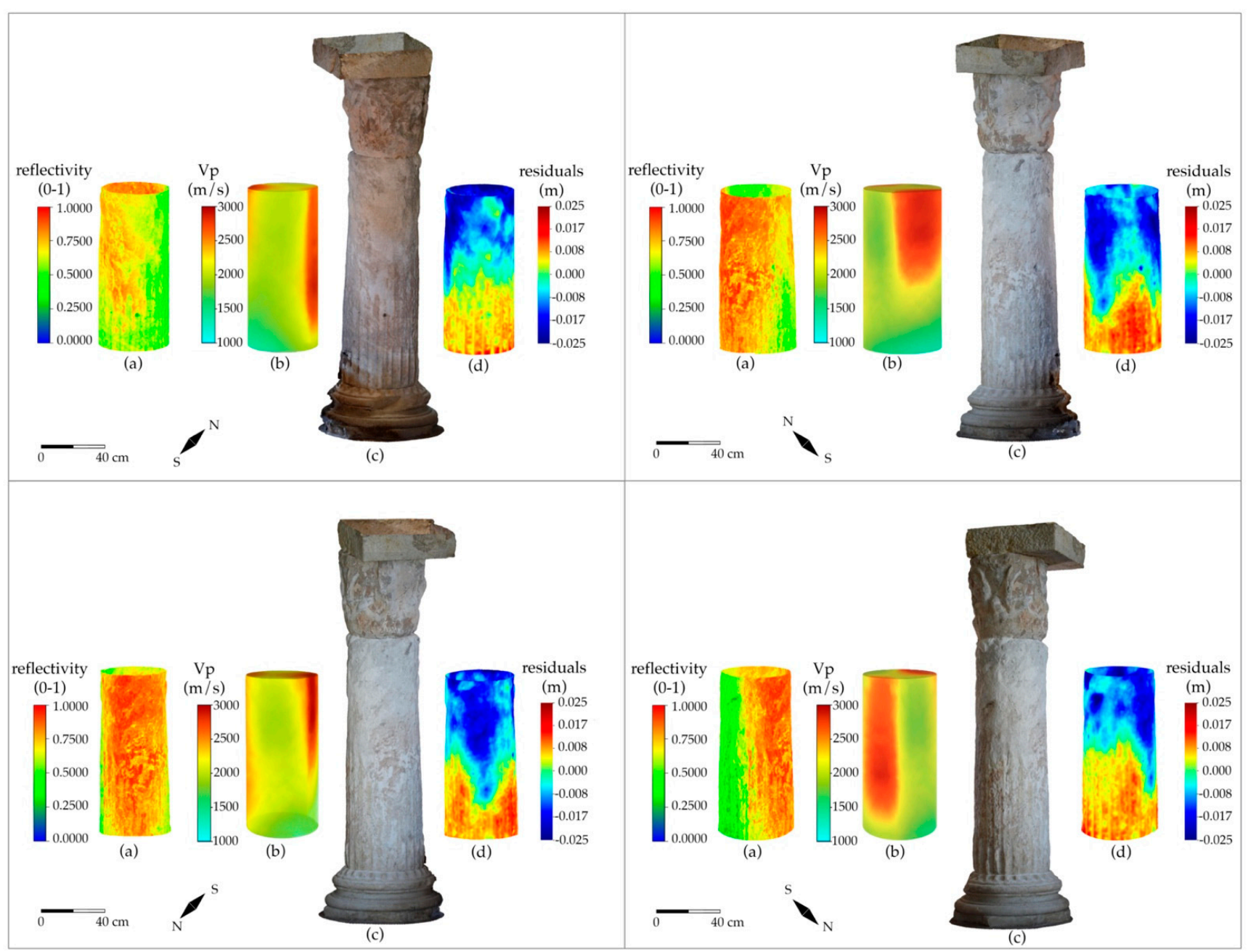

Figure 7. Different views of the 3D high resolution models of the investigated artifact. (a) CRP reflectivity model; (b) ultrasonic velocity model; (c) CRP model of the column; (d) geometrical anomalies. 
The first result of the CRP method is the aggregated unified filtered point cloud, texturised with the natural colours derived from the photogrammetric campaign representing the detailed Carrara marble column under study, with a resolution of $1 \mathrm{~mm}$ or better. This cloud is meshed and reconstructed with the aid of Poisson reconstruction algorithms implemented in the JRC-3D Reconstructor package to fill little holes and to detect an HR reference model that can also be used as metrical reference in future surveys, while preserving the memory of the studied artifact. The derived reflectivity obtained with natural light radiometry gives information on the altered parts of the column surface that can be compared with the other diagnostic tools applied here, in parallel. Taking into account the general definition of reflectivity as the amount of incident energy reflected by the surface of the analysed targets, the higher the reflectivity the higher the roughness of the studied surface. However, the reflectivity also depends on the colours of the studied objects and on the inclination angle of the incident radiation. For this reason, the reflectivity pattern must be complemented with other diagnostic investigations, such as the geometrical anomalies of the material and the velocity patterns given by the ultrasonic methods.

With regards to the geometric anomalies, these are computed with the inspection procedure applied to the HR 3D model of the Carrara marble column under study as residuals, with respect to a cylindrical geometry fitted to the HR 3D model, meshed, and adopted as reference. The results of the inspection procedure applied to the HR model of the column are represented in Figure $7 \mathrm{~d}$, where they are compared with the results of the other diagnostic techniques applied

In particular, in Figure 7, the ancient column is represented from four different points of view to give a better appreciation of the results. In the colour scale of the reflectivity pattern, ranging in the interval from 0 to 1 , the smaller values are represented in Figure $7 \mathrm{a}$ with blue and green colour tones. Conversely, higher values are represented with red tones. The higher values of reflectivity highlight the most affected areas of the column.

In the geometrical anomalies scale, the residuals are scattered in the range $+/-0.025 \mathrm{~m}$, where the positive anomalies are represented in red and the negative ones in blue. By comparing the reflectivity with the geometrical anomalies in the images obtained from different points of view (Figure 7a,d), a swelling is evident in the lower sectors of the column, as well as a superficial degradation of the marble material which appears pulverized. In each figure of the four points of view, positive geometrical anomalies (red tones) are found in the lower part of the column. Moreover, the areas with high reflectivity values mostly coincide with those where the geometrical anomalies are negative. The lack of coincidence is probably due to the presence of marble dust on the column, which is obviously less detectable by reflectivity. This is an indication for suggesting the continuous use of the two imaging maps, which together better define the state of the surfaces.

\subsection{Ultrasonic Tomography}

The results of the 3D ultrasonic tomography give images of the distribution of the longitudinal velocities in the investigated volume. These are shown from different viewpoints in Figure $7 \mathrm{~b}$ to facilitate their comparison with the CRP results (Figure $7 \mathrm{a}, \mathrm{d}$ ).

The results of the tomographic analysis show that the ultrasonic longitudinal velocity ranges between 1000 and $3000 \mathrm{~m} / \mathrm{s}$, denoting differences in the elastic characteristics of the marble building material. These differences are mainly due to the dissolution process of the marble that modifies the pore structure and can change the pore distribution. Microweathering and some forms of marble deterioration that can be recognized through thin section analysis cause a lowering of the elastic characteristics of the material, and thus a decrease in longitudinal velocity values. A great variability in the longitudinal velocity distribution is especially evident in the surface of the marble column, as can be seen from the tomographic volume at different viewpoints (Figure $7 \mathrm{~b}$ ). Sectors characterised by a higher velocity $(2500-3000 \mathrm{~m} / \mathrm{s})$ alternate with others with lower velocity $(1000-1500 \mathrm{~m} / \mathrm{s})$. The latter correspond to surface alteration layers, where deterioration products formed along the surfaces or in crevices created by material detachment. The alteration product 
visible in the low velocity sectors could be due to the decay of calcite caused by the microclimate inside the Basilica, which is characterised by strong humidity. It should be pointed out that the low velocity sectors are almost in correspondence with the high reflectivity sectors (Figure 7a), where the roughness caused by the degradation of the shallow materials is greater. The 3D tomographic and CRP models are representations of different geophysical properties of the same shallow material. Each of these models have different levels of detail and significance, but are connected to each other. Furthermore, the above geophysical properties are linked in a complex way to many rock properties, such as mineralogical composition, texture, density, porosity, and permeability $[3,4,23,26]$. These properties characterise the physical and mechanical conditions of the marble.

To facilitate the diagnostic process inside the column and check the development of the zones characterised by low velocity, while also detecting their geometry and size, a number of tomographic slices corresponding to horizontal sections along the longitudinal development of the investigated structure are represented in Figure 8. The location and orientation of the horizontal slices extracted from the ultrasonic tomography data volume were decided interactively for a clearer visualisation of the internal distribution of the elastic characteristics of the investigated column, while also taking into account the results from a visual inspection (Figure 2) and the 3D CRP models (Figure 7a,c,d). From the visualisation of the tomographic slices, we could better understand the three-dimensional development of the low velocity zones (cyan-green coloured in Figure 8b) associated with the marble degradation. In particular, it can easily be observed that the elastic characteristics of the marble worsen, from the inner part of the column shaft towards its surface. In fact, the lower ultrasonic velocities values (1000-1500 m/s), typical of a degraded marble, generally correspond to the first $5 \mathrm{~cm}$ of the shallow material. This thickness tends to increase in the lower part of the analysed volume of the column (see, for instance, the first two slices from the bottom in Figures 8 and 9), indicating a greater diffusion of the degradation and microfracturing in this part, where positive geometrical anomalies have also been detected. However, apart from this localized sector of the shaft, the stone deterioration is mostly superficial due to the textural characteristics of the investigated Carrara marble. In fact, the lack of intercrystalline porosity and the strong bonds between crystals (Figure 9c,d) hinder degradation in the inner parts of the structure. The surface parts of the column, directly exposed to the humid environment of the basilica, are affected by phenomena of dissolution and exfoliation correlated with the development of new fractures, that allowed for a consequent accumulation of moisture and dirt also recognised by optical microscopy observations. By favouring the degradation of the marble (Figure 9e,f), this condition causes the elastic characteristics of the shallow material to worsen. 


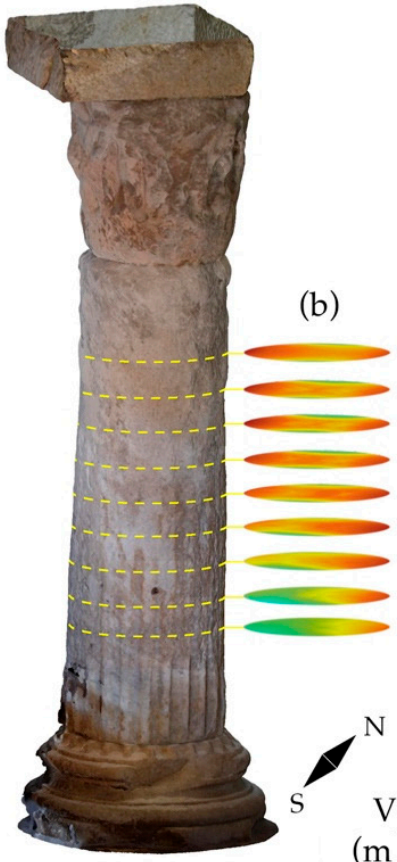

(a)

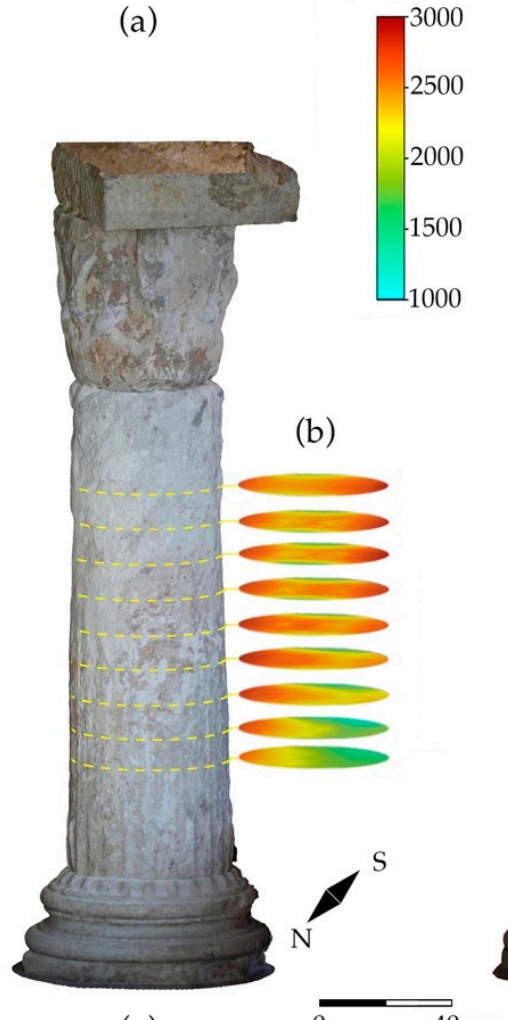

(a)

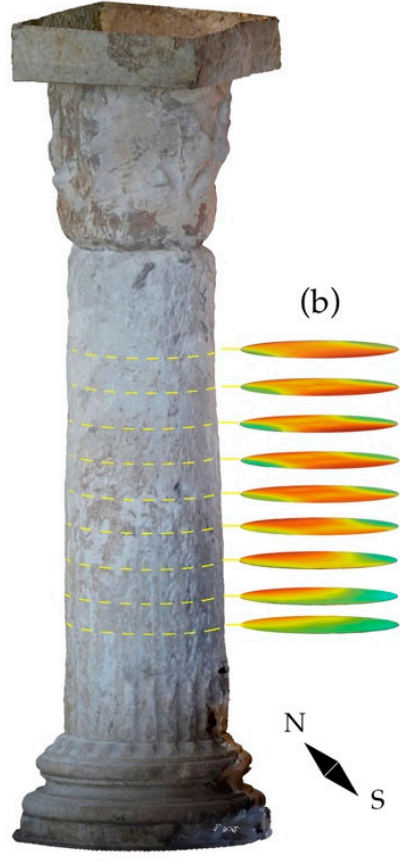

(a)

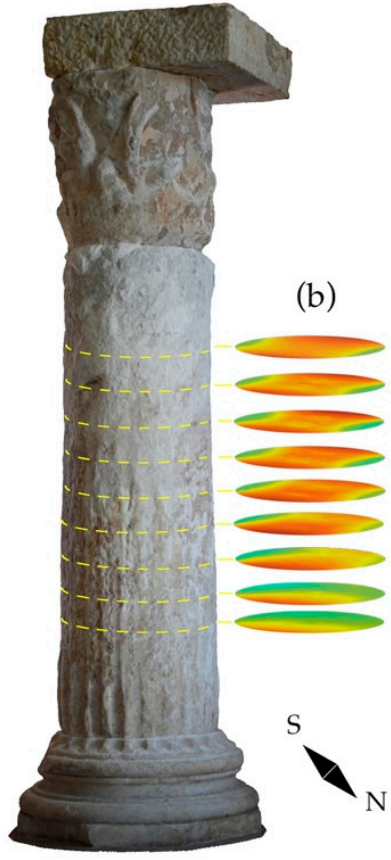

(a)

Figure 8. Different views of the tomographic slices. (a) CRP model; (b) tomographic slices. 


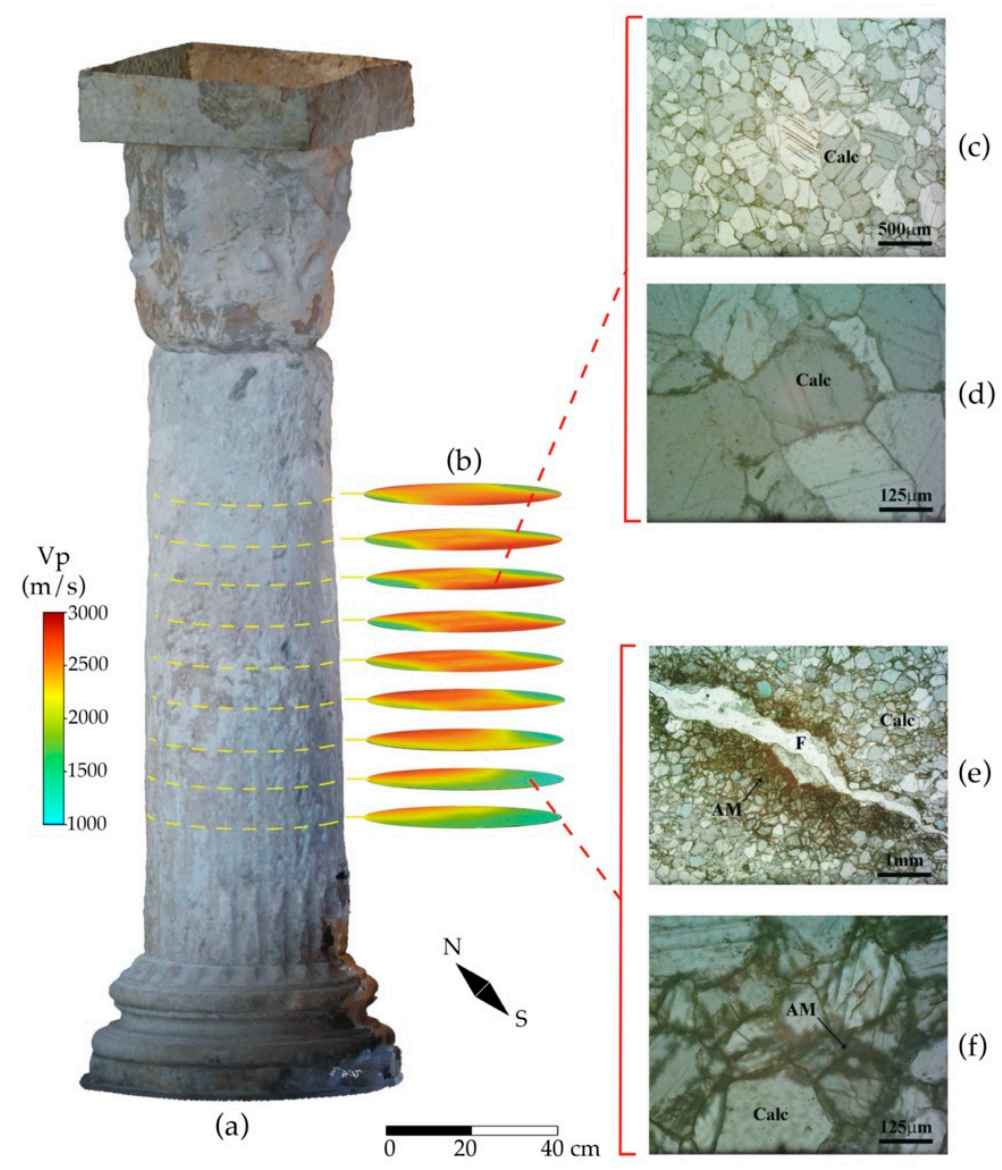

Figure 9. Integrated analysis of the ultrasonic tomography and thin sections. (a) CRP model; (b) tomographic slices; (c,d) thin sections of the marble in a sound sector of the studied column; $(\mathbf{e}, \mathbf{f})$ thin sections of the marble in a degraded sector of the studied column. Calc (calcite); F (fracture); AM (altered material).

\section{Conclusions}

In this study, a Carrara marble column was investigated with a multidisciplinary non-destructive methodology to evaluate its state of conservation, both on the surface and on the internal parts.

The 3D visualisation obtained with photogrammetric and geophysical techniques improves the efficiency, accuracy, and completeness of the diagnostic process on the conservation state of the building materials. By combining the results of the CRP and ultrasonic tomography supported by optical microscopy, an improvement was obtained in the information content on the conditions of the building material in a complex situation. The CRP methodology represents an important tool in the interpretation and quantitative evaluation of the shallow degradation. Furthermore, high resolution 3D models computed with the CRP methodology can be performed at different times, providing a complete and timely view of the external parts of the investigated column. Moreover, it can be useful for a proper documentation and preservation of the historical architectural element. The high reflectivity values, generally close to 1 , were detected in correspondence with the sectors characterised by high surface roughness and low longitudinal velocity. The latter denotes poor elastic characteristics of the shallow material, clearly showing the precariousness of the condition of the column surface. It is clearly shown that the studied column is characterised by severe forms of surface degradation, such as exfoliation and pulverisation, caused by the effects of solubilisation of calcite and intercrystalline decohesion, which worsen the elastic characteristics of the material. The high precision of the position and spatial distribution of the geometrical surface anomalies detected by CRP represent an efficient dataset for the best design and acquisition of the 3D ultrasonic tomography. Positive 
surface geometrical anomalies have been detected in the lower part of the column, where from an analysis of the tomographic slices a decrease in the longitudinal wave velocity is highlighted, both in the shallow and the inner part of the marble. The combination of the results of both independent techniques (CRP and ultrasonic tomography) points to an increase in degradation and microfracturing with consequent swelling in this part of the column shaft. Microweathering and microfracturing were also recognized by the optical microscopy analysis.

From the ultrasonic tomography slices, it could be seen that in the middle and upper part of the column shaft, the degradation of the shallow material did not spread inside the column, where the marble is generally characterised by better elastic characteristics (Vp around $3000 \mathrm{~m} / \mathrm{s}$ ) and therefore, less unaltered. The integration of the different datasets proves more efficient if supported by the knowledge of the petrographic characteristics of the investigated material, especially mineral composition, texture, and porosity. These characteristics affect both the longitudinal wave velocity distribution inside the column and the roughness and morphology of the shallow materials, that affect the geometrical anomalies and the reflectivity detected by the CRP analysis.

In this study, the approach used is supported and validated by the relationships between the different geophysical observations and the petrographic characteristics of the investigated stone material. Useful results that improve the diagnostic process can be obtained by combining different non-invasive techniques into an effective workflow for a complete integration of the independent datasets.

Furthermore, the integrated approach used in this study can give an effective contribution to monument conservation, providing useful knowledge to project the best restoration and to monitor its efficiency in time.

Author Contributions: S.F. and G.C. conceived the integrated non-invasive diagnostic methodology; F.C. contributed to the visual inspection and analysis of the materials; S.F. and F.C. planned and carried out the ultrasonic data acquisition; S.F. processed and interpreted the ultrasonic data with the cooperation of F.C. and performed the integrated ultrasonic and petrographic analysis with F.C. and P.L.; G.C. and M.G.B. carried out the CRP survey and processed and interpreted the CRP data; A.S. provided the support related to the historical and architectural knowledge of the investigated element. All the authors analysed and discussed the results, contributed to the manuscript drafting and revision. All authors have read and agreed to the published version of the manuscript.

Funding: This research was partially funded by Fondo integrativo per la ricerca (Fir)_Annualità 2020-University of Cagliari (Italy). Funding acquisition: S. Fais.

Acknowledgments: The authors would like to thank the Ministero dei Beni e delle Attività Culturali, Polo Museale della Sardegna for their kind permission to work on the San Saturnino Basilica.

Conflicts of Interest: The authors declare no conflict of interest.

\section{References}

1. Montuori, A.; Luzi, G.; Stramondo, S.; Casula, G.; Bignami, C.; Bonali, E.; Bianchi, M.G.; Crosetto, M. Combined use of groundbased systems for Cultural Heritage conservation monitoring. In Proceedings of the 2014 IEEE Geoscience and Remote Sensing Symposium, Quebec City, QC, Canada, 13-18 July 2014; IEEE: Quebec City, QC, Canada, 2014; pp. 4086-4089. [CrossRef]

2. Montuori, A.; Costanzo, A.; Gaudiosi, I.; Vecchio, A.; Apa, M.I.P.; Gervasi, A.; Falcone, S.; La Piana, C.; Minasi, M.; Stramondo, S.; et al. The MASSIMO system for the safeguarding of historic buildings in a seismic area: Operationally-oriented platforms. Eur. J. Remote Sens. 2016, 49, 397-415. [CrossRef]

3. Bianchi, M.G.; Casula, G.; Cuccuru, F.; Fais, S.; Ligas, P.; Ferrara, C. Three-dimensional imaging from laser scanner, photogrammetric and acoustic non-destructive techniques in the characterization of stone building materials. Adv. Geosci. 2018, 45, 57-62. [CrossRef]

4. Casula, G.; Cuccuru, F.; Bianchi, M.G.; Fais, S.; Ligas, P. High resolution 3-D modelling of cylinder shape bodies applied to ancient columns of a church. Adv. Geosci. 2020, 54, 119-127. [CrossRef]

5. Christaras, B.; Cuccuru, F.; Fais, S.; Papanikolaou, H. Application of non destructive ultrasonic techniques for the analysis of the conservation status of building materials in monumental structures. In Engineering Geology for Society and Territory-Volume 8; Springer: Berlin/Heidelberg, Germany, 2015; pp. 139-143. 
6. Fais, S.; Casula, G.; Cuccuru, F.; Ligas, P.; Bianchi, M.G. An innovative methodology for the non-destructive diagnosis of architectural elements of ancient historical buildings. Sci. Rep. 2018, 8, 4334. [CrossRef] [PubMed]

7. Zhang, J.; Khoshelham, K. 3D reconstruction of internal wood decay using photogrammetry and sonic tomography. Photogramm. Rec. 2020, 35, 357-374. [CrossRef]

8. Hatır, M.E.; Korkanç, M.; Başar, M.E. Evaluating the deterioration effects of building stones using NDT: The Küçükköy Church, Cappadocia Region, central Turkey. Bull. Eng. Geol. Environ. 2019, 78, 3465-3478. [CrossRef]

9. Puxeddu, M.; Cuccuru, F.; Fais, S.; Casula, G.; Bianchi, M.G. 3D Imaging of CRP and Ultrasonic Tomography to Detect Decay in a Living Adult Holm Oak (Quercus ilex L.) in Sardinia (Italy). Appl. Sci. 2021, 11, 1199. [CrossRef]

10. Pepe, M.; Costantino, D. Techniques, tools, platforms and algorithms in close range photogrammetry in building 3D model and 2D representation of objects and complex architectures. Comput. Aided Appl. 2020, 18, 42-65. [CrossRef]

11. Moyano, J.; Nieto-Julián, J.E.; Bienvenido-Huertas, D.; Marín-García, D. Validation of close-range photogrammetry for architectural and archaeological heritage: Analysis of point density and 3D mesh geometry. Remote Sens. 2020, 12, 3571. [CrossRef]

12. Prasetyo, Y.; Bashit, N.; Silaen, B. Geometry accuracy analysis of the three-dimensional model using the close-range photogrammetry method for conservation object of culture (case study: Cow Statue, Faculty Of Livestock, Diponegoro University). IOP Conf. Ser. Earth Environ. Sci. 2020, 500, 12043. [CrossRef]

13. Adamopoulos, E.; Rinaudo, F. Close-Range Sensing and Data Fusion for Built Heritage Inspection and Monitoring-A Review. Remote Sens. 2021, 13, 3936. [CrossRef]

14. Iglhaut, J.; Cabo, C.; Puliti, S.; Piermattei, L.; O'Connor, J.; Rosette, J. Structure from Motion Photogrammetry in Forestry: A Review. Curr. For. Rep. 2019, 5, 155-168. [CrossRef]

15. Buill, F.; Núñez-Andrés, M.A.; Costa-Jover, A.; Moreno, D.; Puche, J.M.; Macias, J.M. Terrestrial Laser Scanner for the Formal Assessment of a Roman-Medieval Structure-The Cloister of the Cathedral of Tarragona (Spain). Geosciences 2020, $10,427$. [CrossRef]

16. Kushwaha, S.K.P.; Dayal, K.R.; Raghavendra, S.; Pande, H.; Tiwari, P.S.; Agrawal, S.; Srivastava, S.K. 3D Digital Documentation of a Cultural Heritage Site Using Terrestrial Laser Scanner-A Case Study. In Applications of Geomatics in Civil Engineering; Ghosh, J.K., da Silva, I., Eds.; Lecture Notes in Civil Engineering; Springer: Singapore, 2020; Volume 33, pp. 49-58, ISBN 9789811370663. [CrossRef]

17. Cecchi, G.; Pantani, L.; Raimondi, V.; Tomaselli, L.; Lamenti, G.; Tiano, P.; Chiari, R. Fluorescence lidar technique for the remote sensing of stone monuments. J. Cult. Herit. 2000, 1, 29-36. [CrossRef]

18. Mitchell, J.; Chandrasekera, T.C.; Holland, D.J.; Gladden, L.F.; Fordham, E.J. Magnetic resonance imaging in laboratory petrophysical core analysis. Phys. Rep. 2013, 526, 165-225. [CrossRef]

19. Grinzato, E.; Marinetti, S.; Bison, P.G.; Concas, M.; Fais, S. Comparison of ultrasonic velocity and IR thermography for the characterisation of stones. Infrared Phys. Technol. 2004, 46, 63-68. [CrossRef]

20. Grinzato, E. IR thermography applied to the cultural heritage conservation. In Proceedings of the 18th World Conference on Nondestructive Testing, Durban, South Africa, 16-20 April 2012; Volume 46.

21. Moropoulou, A.; Bakolas, A.; Aggelakopoulou, E.; Pineli, T.; Prassianakis, I.N. Estimation of elastic constants of stones, used in historic monuments, using ultrasonic technique and correlation to their microstructure parameters. In Proceedings of the 3rd International Conference on Non-Destructive Testing of the Hellenic Society for NDT-NDT in Antiquity and Nowadays-SkillsApplications-Innovations, Chania, Greece, 15-18 October 2003; Prassianakis, I.N., Ed.; The Hellenic Society of NDT (HSNT): Athens, Greece, 2003; pp. 242-245.

22. Casula, G.; Fais, S.; Ligas, P. An experimental application of a 3D terrestrial laser scanner and acoustic techniques in assessing the quality of the stones used in monumental structures. Int. J. Microstruct. Mater. Prop. 2009, 4, 45-56. [CrossRef]

23. Cuccuru, F.; Fais, S.; Ligas, P. Dynamic elastic characterization of carbonate rocks used as building materials in the historical city centre of Cagliari (Italy). Q. J. Eng. Geol. Hydrogeol. 2014, 47, 259-266. [CrossRef]

24. Fais, S.; Cuccuru, F.; Ligas, P.; Casula, G.; Bianchi, M.G. Integrated ultrasonic, laser scanning and petrographical characterisation of carbonate building materials on an architectural structure of a historic building. Bull. Eng. Geol. Environ. 2017, 76, 71-84. [CrossRef]

25. Fais, S.; Cuccuru, F.; Casula, G.; Bianchi, M.G.; Ligas, P. Characterization of Rock Samples by A High-Resolution Multi-Technique Non-Invasive Approach. Minerals 2019, 9, 664. [CrossRef]

26. Fais, S.; Casula, G.; Cuccuru, F.; Ligas, P.; Bianchi, M.G.; Plaisant, A.; Pettinau, A. A Contribution to the Geological Characterization of a Potential Caprock-Reservoir System in the Sulcis Coal Basin (South-Western Sardinia). Energies 2019, 12, 4524. [CrossRef]

27. Kahraman, S. Estimating the direct P-wave velocity value of intact rock from indirect laboratory measurements. Int. J. Rock Mech. Min. Sci. 2002, 39, 101-104. [CrossRef]

28. Vasanelli, E.; Colangiuli, D.; Calia, A.; Sileo, M.; Aiello, M.A. Ultrasonic pulse velocity for the evaluation of physical and mechanical properties of a highly porous building limestone. Ultrasonics 2015, 60, 33-40. [CrossRef] [PubMed]

29. Vasconcelos, G.; Lourenço, P.B.; Alves, C.A.S.; Pamplona, J. Ultrasonic evaluation of the physical and mechanical properties of granites. Ultrasonics 2008, 48, 453-466. [CrossRef] [PubMed]

30. Santos-Assunçao, S.; Perez-Gracia, V.; Caselles, O.; Clapes, J.; Salinas, V. Assessment of complex masonry structures with GPR compared to other non-destructive testing studies. Remote Sens. 2014, 6, 8220-8237. [CrossRef] 
31. Anselmetti, F.S.; Eberli, G.P. Sonic Velocity in Carbonate Sediments and Rocks. In Carbonate Seismology; Palaz, I., Marfurt, K.J., Eds.; Society of Exploration Geophysicists: Tulsa, OK, USA, 1997; pp. 53-74. ISBN 978-1-56080-038-5. [CrossRef]

32. Eberli, G.P.; Baechle, G.T.; Anselmetti, F.S.; Incze, M.L. Factors controlling elastic properties in carbonate sediments and rocks. Lead. Edge 2003, 22, 654-660. [CrossRef]

33. Fais, S.; Ligas, P.; Cuccuru, F.; Maggio, E.; Plaisant, A.; Pettinau, A.; Casula, G.; Bianchi, M.G. Detailed Petrophysical and Geophysical Characterization of Core Samples from the Potential Caprock-reservoir System in the Sulcis Coal Basin (Southwestern Sardinia-Italy). Energy Procedia 2015, 76, 503-511. [CrossRef]

34. King, M.S.; Myer, L.R.; Rezowalli, J.J. Experimental studies of elastic-wave propagation in a columnar-jointed rock mass. Geophys. Prospect. 1986, 34, 1185-1199. [CrossRef]

35. Soete, J.; Kleipool, L.M.; Claes, H.; Claes, S.; Hamaekers, H.; Kele, S.; Özkul, M.; Foubert, A.; Reijmer, J.J.G.; Swennen, R. Acoustic properties in travertines and their relation to porosity and pore types. Mar. Pet. Geol. 2015, 59, 320-335. [CrossRef]

36. Weger, R.J.; Baechle, G.T.; Masaferro, J.L.; Eberli, G.P. Effects of porestructure on sonic velocity in carbonates. In Proceedings of the SEG International Exposition and 74th Annual Meeting, Denver, CO, USA, 10-15 October 2004; SEG Technical Program Expanded Abstracts 2004. Society of Exploration Geophysicists: Houston, TX, USA, 2004; Volume 23, pp. 1774-1777. [CrossRef]

37. Siegesmund, S.; Ruedrich, J.; Koch, A. Marble bowing: Comparative studies of three different public building facades. Environ. Geol. 2008, 56, 473-494. [CrossRef]

38. Antonelli, F.; Lazzarini, L. An updated petrographic and isotopic reference database for white marbles used in antiquity. Rendiconti Lincei 2015, 26, 399-413. [CrossRef]

39. Westoby, M.J.; Brasington, J.; Glasser, N.F.; Hambrey, M.J.; Reynolds, J.M. 'Structure-from-Motion' photogrammetry: A low-cost, effective tool for geoscience applications. Geomorphology 2012, 179, 300-314. [CrossRef]

40. Snavely, N.; Seitz, S.M.; Szeliski, R. Modeling the World from Internet Photo Collections. Int. J. Comput. Vis. 2008, 80, 189-210. [CrossRef]

41. Triggs, B.; McLauchlan, P.F.; Hartley, R.I.; Fitzgibbon, A.W. Bundle adjustment-A modern synthesis. In Proceedings of the International Workshop on Vision Algorithms, Corfu, Greece, 21-22 September 1999; pp. 298-372.

42. Campanella, M.; Rossi, G.; Ruggiero, G. JRC 3D Reconstructor ${ }^{\circledR}$ User Manual; Gexcel, Geomatics and Excellence: Brescia, Italy, 2014.

43. CloudCompare CloudCompare (Version 2.11 Beta) [GPL Software]. 2020. Available online: http://www.cloudcompare.org/ (accessed on 20 September 2021).

44. ISRM. The complete ISRM suggested methods for rock characterization, testing and monitoring: 1974-2006. In Suggested Methods Prepared by the Commission on Testing Methods; Ulusay, R., Hodson, J.A., Eds.; International Society for Rock Mechanics, Compilation Arranged by the ISRM Turkish National Group: Ankara, Turkey, 2007; p. 628.

45. ISRM. Upgraded ISRM Suggested Method for Determining Sound Velocity by Ultrasonic Pulse Transmission Technique. In The ISRM Suggested Methods for Rock Characterization; Ulusay, R., Ed.; Testing and Monitoring: 2007-2014; ISRM: Cham, Switzerland; Heidelberg, Germany; New York, NY, USA; Dordrecht, The Netherlands; London, UK, 2014; pp. 95-99.

46. Gilbert, P. Iterative methods for the three-dimensional reconstruction of an object from projections. J. Theor. Biol. 1972, 36, 105-117. [CrossRef]

47. Trampert, J.; Leveque, J.-J. Simultaneous iterative reconstruction technique: Physical interpretation based on the generalized least squares solution. J. Geophys. Res. 1990, 95, 12553-12559. [CrossRef]

48. Phillips, W.S.; Fehler, M.C. Traveltime tomography: A comparison of popular methods. Geophysics 1991, 56, 1639-1649. [CrossRef]

49. Fais, S.; Casula, G. Application of acoustic techniques in the evaluation of heterogeneous building materials. NDT E Int. 2010, 43, 62-69. [CrossRef]

50. Siegesmund, S.; Menningen, J.; Shushakova, V. Marble decay: Towards a measure of marble degradation based on ultrasonic wave velocities and thermal expansion data. Environ. Earth Sci. 2021, 80, 395. [CrossRef] 